\title{
Erratum
}

\section{Genetic studies on the $\beta$ subunit of Escherichia coli RNA polymerase}

\section{Localisation of a region involved in promoter selectivity}

\author{
Robert E. Glass ${ }^{1}$, Steven T. Jones ${ }^{1}$, Vishvanath Nene $^{2}$, Teruaki Nomura ${ }^{3}$, Nobuyuki Fujita ${ }^{3}$, and Akira Ishihama ${ }^{3}$ \\ ${ }^{1}$ Department of Biochemistry, Queen's Medical Centre, Clifton Boulevard, Nottingham, NG7 2UH, England \\ ${ }^{2}$ Department of Pathology, University of Cambridge, Tennis Court Road, Cambridge CB2 1 QP, England \\ ${ }^{3}$ Department of Molecular Genetics, National Institute of Genetics, Mishima, Shizuoka 411, Japan
}

Mol Gen Genet (1986) 203:487-491

Please note the following corrections:

The first line of the footnote to Table 1, p. 488, should read:

$\Delta$ (rpoB) 1570-1 was tested in both the AJ and W 3110 genetic background (see Materials and methods, and Nene and Glass $1984 \mathrm{~b}$ ).

Figure 2A, B, p. 489, has been reprinted so that the bands (transcript ' $i$ ', right panel, B) can be seen more clearly.

田
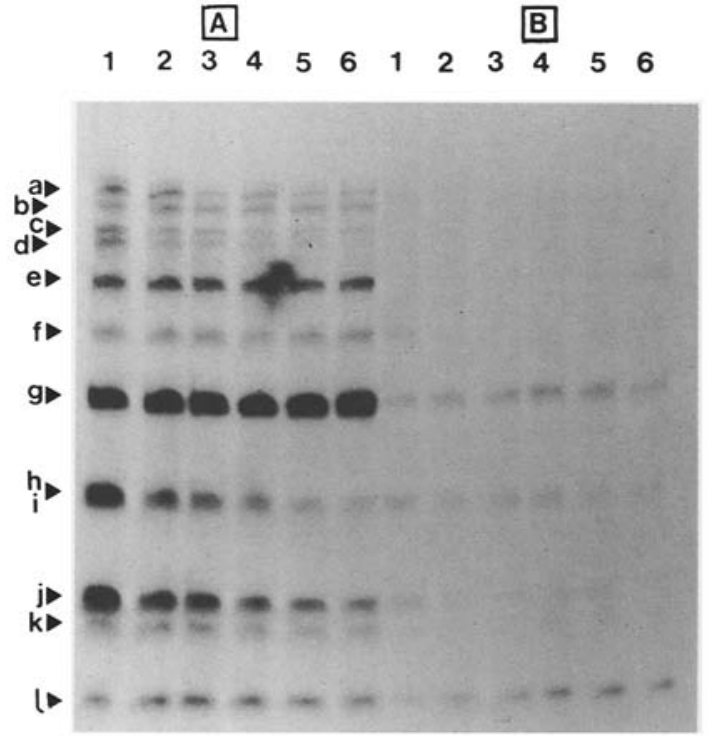

田 $\begin{array}{llll}1 & 2 & 3 & 4\end{array}$

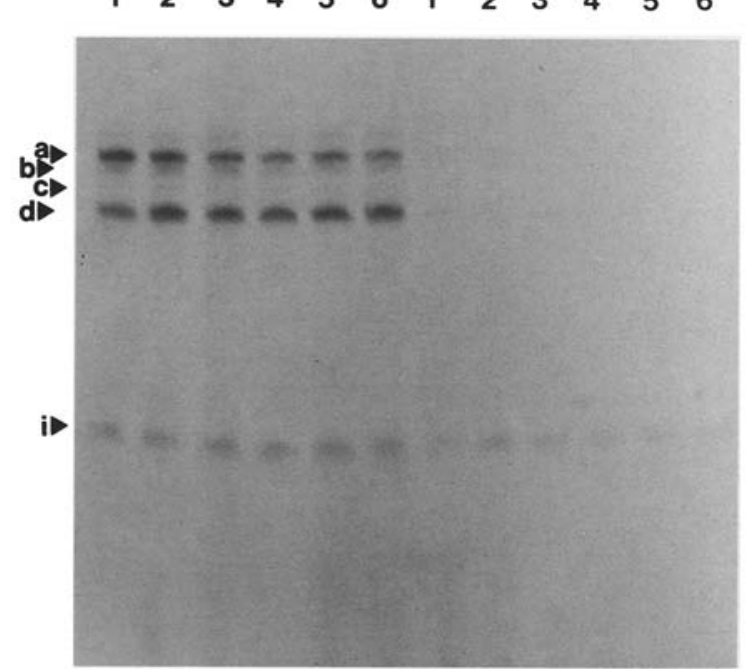

Fig. 2 A, B. Promoter specificity of $\Delta(r p o B) 1570-1$ RNA polymerase. RNA polymerase from $r p o B^{+}$(A) and $A(r p o B) 1570-1$ (B) strains were studied. The left panel shows transcripts synthesised when using all the promoter fragments detailed in Fig. 1: the right panel is for in vitro transcription primed with the $d n a Q / r n h$ and $r e c A$ fragments. The wild-type enzyme employed in these studies was from AJ1: W 3350 RNA polymerase gave near identical results (data not shown) as would be expected. Tracks 1, 2, 3, 4, 5 and 6 in the four experiments are for in vitro transcription in the absence of ppGpp, and in the presence of $0.025,0.05,0.1,0.2 \mathrm{and} 0.4 \mathrm{mM}$, ppGpp, respectively. Transcripts ' $\mathrm{a}$ ', ' $\mathrm{b}$ ', and ' $\mathrm{d}$ ' are initiated from $d n a Q_{\mathrm{P} 1}, r n h$ and $d n a Q_{\mathrm{P} 2}$ (the origin of band 'c' is unknown). Transcripts ' $\mathrm{e}$ ', 'f' and ' 1 ' are uncharacterised products from the rplJp DNA fragments. Band ' $\mathrm{g}$ ' is the trpP product. Transcript ' $h$ ' comes from nusAp which virtually co-migrates with the recAp product, band ' $i$ '. Transcripts ' $\mathrm{j}$ ' is initiated at $r p l J p$. Transcript ' $\mathrm{k}$ ' is from the lacUV5 promoter. The difference in promoter specificity is clearly seen when the in vitro transcription system contains all eleven promoters (viz bands $\mathrm{a}, \mathrm{b}, \mathrm{d}$ and $\mathrm{k}$, left panel) and is emphasised when studying just the dna $Q_{\mathrm{P} 1, \mathrm{P} 2}$ and $r n h$ promoters using recAp as control (compare bands $\mathrm{a}, \mathrm{b}$ and $\mathrm{d}$ to $\mathrm{i}$, right panel). As expected, transcription from rplJp is sensitive to ppGpp: at high concentrations, as has been reported (Kajitani and Ishihama 1984), lac transcription is inhibited (see bands $\mathrm{j}$ and $\mathrm{k}$ in tracks $\mathrm{A} 1-\mathrm{A} 6$, left panel). Some sensitivity to ppGpp is observed with the wild-type enzyme on dnaQ $Q_{\mathrm{P} 1, \mathrm{P} 2}$ and $r n h$ (bands a, b, d) and is much increased with $\Delta(r p o B)$ 1570-1 RNA polymerase (compare tracks A 1-A6 and B1-B 6, right panel)

The following reference should read as follows:

Glass RE, Honda A, Ishihama A (1986a) Genetic studies on the $\beta$ subunit of Escherichia coli RNA polymerase. IX. The role of the carboxy-terminus in enzyme assembly. Mol Gen Genet 203:492-495 